\title{
EDITORIAL
}

\section{Markov model of CLL transplants}

Bone Marrow Transplantation (2012) 47, 1145-1146; doi:10.1038/ bmt.2012.72

The human mind is imperfect-we reach conclusions quickly based mostly on impressions, often coloured by prior experience. In psychology this is referred to as thin-slicing. This is not a new sophisticated reasoning modality but a consequence of evolution: not much time to evaluate a saber-tooth tiger's dinner plans when he appears outside your cave. Interestingly, these quick conclusions often prove as valid as more detailed analyses. However, sometimes they do not-think Herbert Hoover (A detailed description of Herbert Hoover-type error can be found in Blink by Malcolm Gladwell ${ }^{1}$ and elsewhere). Consideration of complex data sometimes intervenes in the quick conclusion process, but only rarely. Moreover, once reaching a conclusion, we have difficulty changing. We selectively seek additional supporting data of whatever quality; discordances are often avoided or conveniently downgraded. If you doubt this process, consider current debates about evolution and abortion. You may rightly ask: what has this to do with medicine? A lot. Physicians are no different in their thought processes than anyone else. When asked the best therapy of CLL they are likely to resort to thin-slicing. Only later may they consider data supporting or refuting their initial impression.

Markov-modeling, more properly called a Markov decisionprocess, is a mathematical approach to decision-making in a situation where outcomes are partly random and partly under the control of a decision maker (like you or me); for reviews see Robins and Hernán, ${ }^{2}$ Robins and Hernán ${ }^{3}$ and Matheson. ${ }^{4}$ They are useful for studying optimization problems like: what is the best therapy of advanced chronic lymphocytic leukemia (CLL) absent definitive data from randomized clinical trials. A Markov decision-process is a discrete-time stochastic control process. At each time step the process is in some state and the decision-maker may choose any action available in that state. The process responds at the next time-step by randomly moving into a new state and giving the decision-maker a corresponding reward (or punishment). The probability that the process moves into its new state is influenced by the chosen action given by the state transition function. Thus, the next state depends on the current state and the decision maker's action. But given a specific state and action it is conditionally independent of all previous states and actions, namely, the state transitions have the Markov-property. If this sounds confusing just have a look at the Figure 1: it will become crystal clear immediately. It is important, regardless of how sophisticated this model appears, to recall Markov-modeling is an over simplification used to give crude approximations to reality. Reliability of the process depends on the quality of information entered into the model as the outcome of transition states.

When is Markov-modeling useful? As my colleagues and I discussed in a recent (mostly ignored or disbelieved) review in Bone Marrow Transplantation, there are several ways to determine the relative effectiveness of different therapies, say transplants versus anti-cancer chemotherapy or immune therapy in CLL. The gold standard is results of one or more randomized clinical trials but sometimes these have (seemingly) contradictory outcomes. In other instances, like advanced CLL, randomized clinical trials are unlikely to be done. This leaves us with alternate approaches like meta-analyses, observational databases, quantization of expert opinion and Markov-modeling.

In this issue Kharfan-Dabaja and colleagues ${ }^{6}$ tackle the issue of the better therapy of CLL: anti-cancer drugs and antibodies or a reducedintensity allotransplant. They use Markov-modeling with various transition states (but not graft-versus-host disease) to see which therapy performs best in persons with advanced disease. They declare reduced-intensity transplants the winner but rightly pointout limitations of this approach. Their strategy is similar to that used by Cutler and colleagues and others to model conventional therapy versus allotransplants in myelodysplastic syndrome (MDS). ${ }^{7}$ And modeling, of course, needs to be repeated when either or both of the therapies being compared change. ${ }^{8}$ As we pointed out in our review, conclusions from alternatives to randomized trials are sometimes all we have but our confidence in the conclusion is greatly-strengthened when conclusions from several approaches, like analyses from observational databases and quantization of structured expert opinion, are concordant.

There are a few issues to quibble with. For example, the authors refer to these as reduced-toxicity regimens. This is, unfortunately, often a fantasy. Although they are reduced-intensity, several analyses from the CIBMTR, indicate comparable treatment-related mortality (TRM) with conventional and reduced-intensity transplants (for example, Luger et al. ${ }^{9}$ ). The authors also failed to model a GvHD state for mortality because it was included in non-relapse mortality (NRM) state in the data they used. Although true, it is a major and discrete cause of loss of quality-of-life (QoL), especially in older persons. They tried to account for this limitation with other approaches, like sensitivity analyses. Because they used a literature-based approach, we cannot know what publication selection-biases might operate with either therapy being evaluated. This is especially so of phase -1 and -2 studies and for trials published before mandatory pre-trial registration was begun. Another issue is use of a base-case age of 50 years which is hardly representative of persons with CLL and not the major focus of

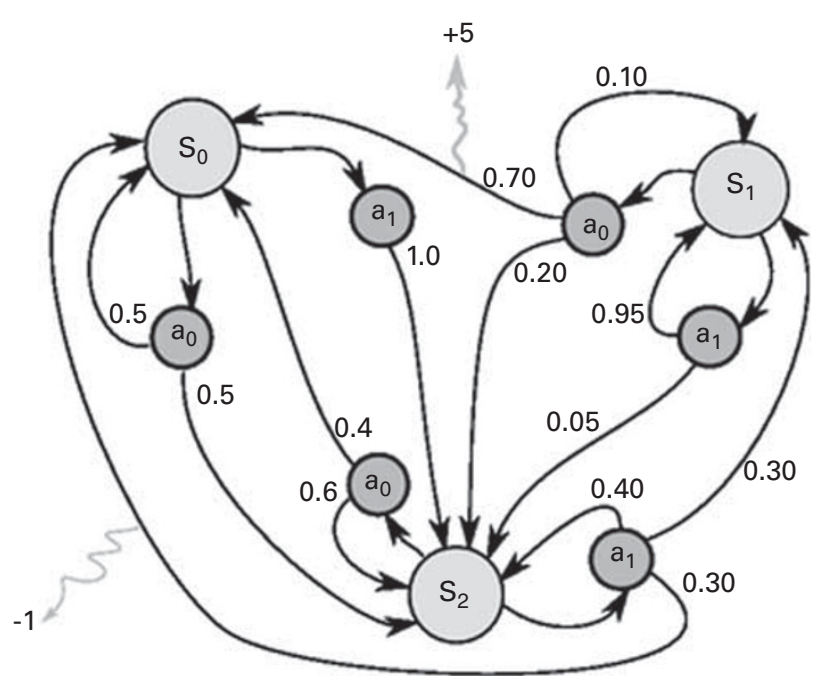

Figure 1. Example of a simple Markov decision process with 3 states and 2 actions. 
reduced-intensity transplants. The authors tested older ages (up to 70 years) in sensitivity-analyses but these data are less convincing. The authors also assumed an optimal state of health of persons starting either therapy. Why is unclear; most persons with advanced CLL (and some of their physicians) can only wish to be in this condition. But these points do not detract from the decent effort to give us an answer. Perhaps the most important issue is Markovmodeling needs to reflect uncertainties in the inputs and outputs to be credible and useful. However, the bottom line is that in most regards what the authors present is more a meta-analysis of available clinical data than a Markov-decision analysis.

Finally, the key issue for those of us who treat CLL is slightly different than the question addressed by Kharfan-Dabaja and colleagues. It is not whether to consider a reduced-intensity allotransplant versus therapy-alternatives but in whom and when. New drugs for CLL are emerging rapidly including bendamustine, ${ }^{10}$ Bruton-type kinase inhibitors, ${ }^{11,12}$ adoptive immune-therapy with expanded, genetically-engineered autologous T-cells and chimeric anti-CD19 antibodies $^{13}$ and lenalidomide. ${ }^{14}$ My colleague Michael Keating claims he will have CLL cured within three years (only because he is lazy [his comment]); let's give him five. In the interim, data from the analysis of Kharfan-Dabaja and colleagues are helpful when combined with some clinical common sense (paradoxically, a rare commodity).

\section{CONFLICT OF INTEREST}

RPG is an employee of Celgene Corp., Summit, NJ, USA.

\section{ACKNOWLEDGEMENTS}

Prof John P Klein (Medical College Wisconsin) kindly reviewed an earlier version of the typescript and made helpful suggestions. He, and my wife, said it was 'rambling' and suggested cutting the text by 50 percent and deleting any mention of Bayesian statistics. My cat agreed. RPG acknowledges support from the NIHR Biomedical Research Centre funding scheme.

RP Gale

Haematology Section, Division of Experimental Medicine, Department of Medicine, Imperial College, London, UK

\section{REFERENCES}

1 Gladwell M. Blink. The power of thinking without thinking. Little, Brown and Company: New York, 2005.

2 Robins JM, Hernán MA. Instruments for Causal Inference An Epidemiologist's dream? Epidemiology 2006; 17: 360-372.

3 Robins JM, Hernán MA. Estimating causal effects from epidemiological data. J Epidemiol Comm Health 2006; 60: 578-586.

4 Matheson Jim E (ed). Readings on the Principles and Applications of Decision Analysis (2 volumes). Strategic Decisions Group: Menlo Park, CA, 1884.

5 Gale RP, Eapen M, Logan B, Zhang MJ, Lazarus HM. Are there roles for observational studies and structured quantification of expert opinion to answer therapy controversies in transplants? Bone Marrow Transplant 2009; 43: 435-436.

6 Kharfan-Dabaja M, Pidala J, Kumar A, Terasawa T, Djulbegovic B. Comparing efficacy of reduced toxicity allogeneic hematopoietic cell transplantation versus conventional chemo-(immuno) therapy in patients with relapsed or refractory chronic lymphocytic leukemia: a Markov decision analysis. Bone Marrow Transplant 2012.

7 Cutler CS, Lee SJ, Greenberg P, Deeg HJ, Perez WS, Anasetti C et al. A decisionanalysis of allogeneic bone marrow transplantation for the myelodysplastic syndromes: delayed transplantation for low-risk myelodysplasia is associated with improved outcome. Blood 2004; 104: 579-585.

8 Koretch J, Pidela J, Perez WS, Deeg HJ, Garcia-Manera G, Malcovati L et al. A decision analysis of reduced-intensity conditioning allogeneic hematopoietic stem cell transplantation for older patients with de-novo myelodysplastic syndrome (MDS); Early transplantation offers survival benefits in higher-risk MDS Blood 2011; 118: 56-57 (Abstract).

9 Luger SM, Ringdén O, Zhang MJ, Pérez WS, Bishop MR, Bornhauser M et al. Similar outcomes using myeloablative vs reduced intensity allogeneic transplant preparative regimens for AML or MDS. Bone Marrow Transplant 2012; 47: 203-211.

10 Jamshed S, Cheson BD. Role of bendamustine in the treatment of chronic lymphocytic leukemia. Onco Targets Ther 2009; 18: 43-49.

11 Byrd JC, Blum KA, Burger JA, Coutre SE, Sharman RR, Furman IW. Activity and tolerability of the Bruton's tyrosine kinase (Btk) inhibitor $\mathrm{PCl}-32765$ in patients with chronic lymphocytic leukemia/small lymphocytic lymphoma (CLL/SLL): Interim results of a phase Ib/ll study. J Clin Oncol 2011; 29(Suppl; Abstr 6508).

12 Fowler N, Sharman JP, Smith SM, Boyd T, Grant B, Kolibaba KS. The BtK inhibitor $\mathrm{PCl}-32765$, induces durable responses with minimal toxicity in patients with relapsed/refractory Bcell malignancies: results from a phase I study. Blood 2010; 116: 964 (Abstr)

13 Porter DL, Levine BL, Kalos M, Bagg A. June CH. Chimeric antigen receptormodified T cells in chronic lymphoid leukemia. N Engl J Med 2011; 365: 725-733.

14 Badoux XC, Keating MJ, Wen S, Lee BN, Sivina M, Reuben J et al. Lenalidomide as initial therapy of elderly patients with chronic lymphocytic leukemia. Blood 2011; 118: 3489-3498. 